\title{
Renal tubulointerstitial tissue damage, central pressure and vascular function in patients with untreated primary arterial hypertension
}

\author{
Rafał Bednarski', Piotr Kubalski' , Anna Stefańska', Grażyna Odrowąż-Sypniewska', Jacek Manitius' \\ ${ }^{1}$ Chair and Clinic of Nephrology, Arterial Hypertension and Internal Diseases of the Nicolaus Copernicus University \\ Collegium Medicum in Bydgoszcz, Poland \\ ${ }^{2}$ Euromedica Non-Public Health Care Centre in Grudziądz, Poland \\ ${ }^{3}$ Chair and Department of Laboratory Medicine of the Nicolaus Copernicus University Collegium Medicum in Bydgoszcz, Poland
}

\section{Summary}

Background The aim of the study was to examine the correlation of the conventional method of arterial pressure measurement in the brachial artery and non-invasive aortic pressure measurement by applanation tonometry with vascular and left ventricular structure and function. An attempt was made at determining a correlation of morphological and functional changes within the cardiovascular system with selected parameters of renal filtration function and the renal interstitium in patients with previously untreated primary arterial hypertension.

Material and methods 25 patients with untreated primary arterial hypertension without albuminuria and 15 healthy volunteers underwent arterial pressure measurement with a standard mercury sphygmomanometer using the Korotkoff technique and non-invasive measurement of aortic pressure by applanation tonometry using a SphygmoCor device. For all subjects, the concentrations of creatinine, uric acid, $1,25(\mathrm{OH})_{2} \mathrm{D}_{3}$, erythropoietin, and 25-hour NAG excretion were determined and GFR was estimated using the MDRD equation. PWV measurement was performed using a SphygmoCor device, whereas IMT was measured by ultrasound.

Results Hypertensive patients showed higher values of arterial pressure compared to the control group: SBP, DBP, PP, MAP, as well as CSP, CDP, CPP and MCAP. In both the studied and the control group, the following statistically significant positive correlations were found: CPP vs IMT and CPP vs AIx.

Only in the studied group, the following positive linear correlations were found: NAG vs PWV ( $R=0.46 ; p=0.019)$; NAG vs IMT $(R=0.36 ; p=0.078)$. In the multiple regression model, a statistically significant positive effect was found of PWV and IMT [PWV ( $\beta$ 0.41; $\mathrm{p}=0.0158)$, IMT $(\beta 0.49 ; \mathrm{p}=0.0048)]$ on the dependent variable NAG $\left(\mathrm{R}^{2}=\right.$ $=0.503)$ in hypertensive patients. eGFR or uric acid concentration in serum included additionally in the model had no statistically significant effect on the dependent variable NAG $(p=0.9307$ and $p=0.4938$, respectively).

Conclusions Damage to the renal tubulointerstitial tissue in hypertensive patients is concomitant with a decrease in vascular resistance. CPP may constitute a useful parameter for assessing the development of atherosclerotic lesions in vessels and the function of the left ventricle of the heart.

key words: arterial hypertension, CPP, NAG, vessels

Arterial Hypertension 2015, vol. 19, no 1, pages: 29-38

DOI: $10.5603 / A H .2015 .0006$

\section{Background}

Arterial hypertension constitutes one of the most critical risk factors for complications affecting the cardiovascular system. Recognized as one of the most common chronic diseases, it poses a major medical, social and economic problem.

Address for correspondence: Rafał Bednarski, MD

Chair and Clinic of Nephrology, Arterial Hypertension and Internal Diseases, Antoni Jurasz University Hospital no. 1 in Bydgoszcz ul. Marii Skłodowskiej-Curie 9, 85-094 Bydgoszcz, tel: (052) 585-40-30, fax: (052) 585-40-30 
Measuring central blood pressure in patients with arterial hypertension attracts growing attention due to its predictive value in terms of cardiovascular events, as well as the varying effects of antihypertensive drugs on central pressure as compared to brachial artery pressure. Conventional sphygmomanometry employed as a fundamental method for measuring arterial blood pressure allows obtaining the values of systolic and diastolic pressure solely in the brachial artery. Arterial pressure measurement carried out using the traditional method does not reflect the actual pressure in the aorta or the left ventricle during systole.

Systolic blood pressure (SBP) and pulse pressure (PP) in the brachial artery are physiologically higher than central systolic pressure (CSP) and central pulse pressure (CPP) [1]. In contrast, brachial diastolic blood pressure (DBP) is slightly lower than central diastolic pressure (CDP), but the values are almost identical with respect to mean pressure [1].

A difference of 6-11 $\mathrm{mmHg}$ in the values of CSP and CPP between the carotid artery and the brachial artery was found in a study by Safar et al. [2], carried out on a group of patients receiving long-term treatment for arterial hypertension. Pressure augmentation was significantly lower in a group of patients with optimal and normal arterial pressure (6.6$-8.6 \mathrm{mmHg}$ for SBP and $6.8-7.4 \mathrm{mmHg}$ for PP) as compared to a group of patients with normal-high arterial pressure and stage 1, 2 and 3 hypertension (9.7-11.3 $\mathrm{mmHg}$ for SBP and $10.1-11.3 \mathrm{mmHg}$ for $\mathrm{PP}$ ) determined from measurements in the brachial artery [2].

Despite the fact that central pressure seems to be more effective in estimating the risk of cardiovascular complications of hypertension than the value obtained through standard measurement in the brachial artery, current guidelines on the diagnosis and treatment of hypertension are based solely on the conventional pressure measurement method [3]. This might result from the fact that normal central pressure values have not been determined and that the correlations between central and peripheral arterial pressure in different populations or age groups have not been discovered as yet. A study carried out by McEniery et al. [4] found that CSP in a group of patients with normal systolic pressure (SBP in the range of $120-129 \mathrm{mmHg}$ ) measured by the oscillometric method in the brachial artery fell within the value range of approximately $90-125 \mathrm{mmHg}$, whereas in a group of patients with stage 1 hypertension (SBP in the range of $140-159 \mathrm{mmHg}$ ) CSP was approximately $110-158 \mathrm{mmHg}$. With respect to the classification of arterial hypertension based on the conventional measurement method, $32 \%$ of men and $10 \%$ of women with normal SBP had the same values of CSP as patients with stage 1 hypertension [4]. The results suggest that the total risk for cardiovascular events may be estimated inaccurately in patients with arterial hypertension classified solely on the basis of conventional measurements in the brachial artery. Some of the patients whose pressure is classified as normal on the basis of conventional sphygmomanometry measurements may actually be at a higher cardiovascular risk resulting from the value of central pressure. Likewise, in patients with increased brachial systolic pressure and normal central pressure, arterial pressure measurement based solely on the conventional method may overestimate cardiovascular risk and lead to administering too intensive antihypertensive pharmacological treatment.

Currently, much attention is focused on the estimation of early complications developing in the course of arterial hypertension. Owing to the introduction of novel, non-invasive diagnostic methods, significant advancements have been made allowing assessing the structure and function of the cardiovascular system. This makes it possible to estimate early changes within the cardiovascular system preceding the development of atherosclerosis in patients with primary arterial hypertension. A significant role in assessing the degree of arterial wall remodelling is played by measurement of carotid intima-media thickness (IMT) by Doppler ultrasound and measurement of aortal pulse wave velocity (PWV) between the carotid and the femoral artery.

A special role in the complex, multifactorial pathogenesis of primary arterial hypertension is assigned to the regulation of sodium and water excretion by the kidneys [5]. Changes in arterial hypertension result in subtle changes in renal blood flow which in turn lead to significant changes in sodium and water excretion through the kidneys, and thus make it imperative that arterial pressure be maintained at a constant level. An impairment of renal mechanisms regulating sodium excretion and the volume of body fluids underlie the development of arterial hypertension. One of the hypotheses assumes that sodium-sensitive hypertension results mainly from acquired minor damage to the renal interstitium whereby kidney function remains unchanged or only slightly impaired, while urinalysis results are normal or indicate only albuminuria [6]. Therefore, arterial hypertension diagnosed as primary may in fact be a manifestation of functional and 
then morphological damage to the kidneys which occurs subclinically.

The aim of the study was:

1. an assessment of the correlations of conventional arterial pressure measurement in the brachial artery and non-invasive central aortic pressure measurement by applanation tonometry with:

- the structure and function of arterial vessels and the left ventricle of the heart,

- selected parameters of renal filtration function and the renal interstitium;

2. an attempt at finding correlations of morphological and functional changes in the cardiovascular system with selected parameters of renal filtration function and the renal interstitium in patients with previously untreated primary arterial hypertension.

\section{Material and methods}

The study was performed on a group of $25 \mathrm{pa}$ tients (9 women and 16 men) aged 21-61 with previously untreated primary arterial hypertension.

The criteria for exclusion were: secondary arterial hypertension, eGFR $<60 \mathrm{ml} / \mathrm{min} / 1.73 \mathrm{~m}^{2}$, albuminuria, erythrocyturia, diabetes, systemic diseases, neoplastic disease, lack of patient consent to participate in the study.

The control group consisted of 15 healthy volunteers ( 6 women and 9 men) with normal arterial pressure values, whose age matched that of the studied group. The study protocol KB/447/2006 was approved by the Bioethics Committee of the Nicolaus Copernicus University Collegium Medicum in Bydgoszcz.

Each patient underwent a physical examination and an interview in outpatient conditions. Arterial blood pressure was measured using a mercury sphygmomanometer after no less than 10 minutes' rest in sitting position in a quiet room. The first and fifth Korotkoff sounds were used to determine the values of systolic and diastolic arterial pressure, respectively. Arterial pressure measurement was taken using a cuff whose length and width were adjusted to the arm circumference. Arterial hypertension was diagnosed when mean values of arterial pressure (calculated from at least two measurements taken during two separate visits) were equal to or higher than $140 \mathrm{mmHg}$ for systolic pressure and/or $90 \mathrm{mmHg}$ for diastolic pressure. The measurements were then used to calculate mean arterial pressure (MAP) and pulse pressure (PP).
Mean arterial pressure was calculated from the formula:

$$
\mathrm{MAP}(\mathrm{mmHg})=\mathrm{DBP}+1 / 3 \times(\mathrm{SBP}-\mathrm{DBP})
$$

Pulse pressure was calculated from the formula:

$\mathrm{PP}(\mathrm{mmHg})=\mathrm{SBP}-\mathrm{DBP}$

All subjects underwent echocardiographic examination of the heart, ultrasound examination of carotid arteries to determine IMT, and analysis of PWV and pulse waveform.

\section{Echocardiographic examination}

Echocardiographic examination was performed using ALOKA SSD-3500SV ultrasound scanner with the transducer set at the frequency of $2.5 \mathrm{MHz}$. Left ventricular mass (LVM) was calculated using the formula introduced by Devereux et al. [7]. Left ventricular mass index (LVMI) was calculated as the ratio of LVM to body surface area (BSA). Mitral valve flow was recorded using pulsed-wave Doppler ultrasound, in an apical four-chamber view, with the sample volume placed at the tips of open mitral valve leaflets. In this manner, the following mitral flow parameters were measured:

- E - early filling peak velocity $(\mathrm{m} / \mathrm{s})$, and

- A - peak flow velocity during atrial systole $(\mathrm{m} / \mathrm{s})$

E/A ratio was calculated from the obtained parameters.

\section{Ultrasound examination \\ of the carotid arteries}

Ultrasound examination of the carotid arteries was performed using ALOKA SSD-3500SV ultrasound scanner with the transducer set at the frequency of 7.5 MHz. The measurement was taken in areas with no atherosclerotic plaque in the common carotid artery, the carotid sinus and the cervical segment of the internal carotid artery, displaying at least $10 \mathrm{~mm}$ of the length of the examined fragment. IMT was calculated as the arithmetic mean of 6 measurements.

\section{Pulse wave analysis}

Analysis of PWV and pulse waveform was performed by applanation tonometry using the SphygmoCor SCOR-PVx no. 01213 system. Applanation tonometer no. 318858 was used to detect pulse wave.

\section{Pulse wave velocity}

PWV was measured by consecutively recording pulse wave in the carotid and femoral arteries, and measuring the distance between the measurement points and the jugular notch. The system's software 
measured the time interval between R-wave peak in the electrocardiogram and the foot of the pulse wave (intersecting tangents) for both examined arteries. Time $(t)$ between the occurrence of pulse wave in the carotid and femoral arteries was measured automatically. Pulse wave distance (d) was calculated form the formula: $\mathrm{d}=$ (distance between the jugular notch of the sternum and the measurement point on the femoral artery) - (distance between the jugular notch of the sternum and the measurement point on the carotid artery). Distances were measured using a measuring tape. PWV was calculated using the equation PWV $=\mathrm{d} / \mathrm{t}$ and expressed in $(\mathrm{m} / \mathrm{s})$. The criterion for the validity of the study was accepted as standard deviation of the said measurements lower than $6 \%$, and standard deviation of the calculated PWV lower than $10 \%$.

\section{Central pressure and other pulse wave parameters}

Central pressure, augmentation pressure (AP) and augmentation index (AIx) were calculated by mathematical analysis - the so-called transfer function - detecting the pulse wave of the radial artery for at least $12 \mathrm{~s}$. An application in the device performed aortic waveform reconstruction. Before recording pulse wave in the radial artery, arterial pressure in the brachial artery was measured using the oscillometric method.

\section{Laboratory testing}

In the subsequent stage, subjects participating in the study were instructed in terms of performing a 24-hour urine collection. 24-hour creatinine clearance, uric acid clearance and albuminuria were analysed in 24-hour urine samples on the day of their collection. The remaining portion of urine was centrifuged and frozen at $-70^{\circ} \mathrm{C}$ for further determination of $\mathrm{N}$-acetyl-beta-D-glucosaminidase (NAG).

On the day following the 24-hour urine collection, the subjects underwent a peripheral blood draw after overnight fasting. On the day of the blood draw, a portion of the serum was analysed for the concentration of glucose, creatinine and uric acid. The remaining portion of serum was apportioned into Eppendorf test tubes and frozen at $-70^{\circ} \mathrm{C}$ for further analysis, i.e. the concentration of erythropoietin, 25-hydroxycholecalciferol $\left[25(\mathrm{OH}) \mathrm{D}_{3}\right]$ and 1,25-dihydroxycholecalciferol $\left[1,25(\mathrm{OH})_{2} \mathrm{D}_{3}\right]$.

Glomerular filtration rate (eGFR) was estimated using the Modification of Diet in Renal Disease (MDRD) formula [8]:
eGFR $\left(\mathrm{m} / / \mathrm{min} / 1.73 \mathrm{~m}^{2}\right)=186 \times(\text { creatinine concentration })^{-1.154} \times(\text { age })^{-0.203} \times \mathrm{C}$

Fractional uric acid excretion $-\mathrm{FE}_{\mathrm{UA}}(\%)$ was calculated from the formula:

$$
\mathrm{FE}_{\mathrm{UA}}(\%)=\mathrm{UA}_{\mathrm{ur}} / \mathrm{UA}_{s} \times \mathrm{Cr}_{\mathrm{s}} / \mathrm{Cr}_{\mathrm{ur}} \times 100
$$

where:

$\mathrm{UA}_{\text {ur }}$ - concentration of uric acid in urine $\mathrm{UA}_{\mathrm{s}}$ - concentration of uric acid in serum $\mathrm{Cr}_{\mathrm{s}}$ - concentration of creatinine in serum $\mathrm{Cr}_{\mathrm{ur}}$ - concentration of creatinine in urine

\section{Statistical analysis}

The obtained results were analysed statistically. The compliance of the distribution of variables with normal distribution was analysed using the Shapiro-Wilk test. Student's t-test for independent variables was used to compare mean values for samples with close-to-normal distribution. Variance homogeneity was assessed using Levene's test. When the distribution was significantly different from normal, the significance of differences between groups was determined using the Mann-Whitney nonparametric $\mathrm{U}$ test. Correlation between two variables was calculated using the Pearson and Spearman correlation coefficient. The multiple regression method was used to analyse the cumulative effect of multiple variables on the dependent variable. The statistical significance level was accepted as $\mathrm{p}<0.05$. All calculations were performed using the Statistica 7.1 software.

\section{Results}

Clinical characteristics of subjects from the group with arterial hypertension and from the control group are presented in Tables I-V.

Data presented in Tables II-III demonstrate that no statistically significant differences were found with respect to the values of selected parameters of renal filtration function and the renal interstitium between the studied groups. 24-hour excretion of NAG in urine was at the borderline of statistical significance.

In the group of hypertensive subjects, a statistically significant lower value of the E/A ratio was found as compared to the control group.

Data presented in Tables VI-VII show that statistically significant positive correlations of CPP with IMT and AIx values were found both in the group of hypertensive patients and the control group. Moreover, a statistically significant negative correlation between CPP and E/A ratio was found in the group of hypertensive subjects. 
Table I. Basic characteristics of the studied groups

\begin{tabular}{|c|c|c|c|c|c|}
\hline \multirow[t]{2}{*}{ Parameter } & \multicolumn{2}{|c|}{$\begin{array}{l}\text { Studied group } \\
n=25\end{array}$} & \multicolumn{2}{|c|}{$\begin{array}{c}\text { Control group } \\
\mathrm{n}=15\end{array}$} & \multirow[t]{2}{*}{$\mathbf{P}$} \\
\hline & Mean & SD & Mean & SD & \\
\hline Age (years) & 43.52 & 11.55 & 40.67 & 10.90 & 0.4448 \\
\hline $\mathrm{BMI}\left[\mathrm{kg} / \mathrm{m}^{2}\right]$ & 28.72 & 4.00 & 25.04 & 4.00 & 0.0076 \\
\hline SBP [mmHg] & 163.40 & 13.05 & 119.00 & 9.10 & 0.0001 \\
\hline $\mathrm{DBP}[\mathrm{mmHg}]$ & 101.20 & 9.60 & 77.67 & 6.51 & 0.0001 \\
\hline MAP [mmHg] & 121.88 & 9.75 & 91.47 & 6.62 & 0.0001 \\
\hline $\mathrm{PP}[\mathrm{mmHg}]$ & 62.20 & 10.42 & 41.33 & 7.43 & 0.0001 \\
\hline $\mathrm{CSP}[\mathrm{mmHg}]$ & 144.32 & 19.59 & 114.20 & 9.37 & 0.0001 \\
\hline $\mathrm{CDP}[\mathrm{mmHg}]$ & 101.80 & 10.79 & 83.80 & 7.09 & 0.0001 \\
\hline MCAP [mmHg] & 115.90 & 13.20 & 93.90 & 6.80 & 0.0001 \\
\hline $\mathrm{CPP}[\mathrm{mmHg}]$ & 42.52 & 11.97 & 30.40 & 8.93 & 0.0016 \\
\hline
\end{tabular}

In the group of hypertensive subjects, increased values of the following were found: BMI, SBP and DBP measured conventionally in the brachial artery, as well as MAP and PP.

Moreover, increased values of CSP, CDP, MCAP and CPP were found in the group of hypertensive subjects.

Abbreviations: BMI — body mass index, CDP — central diastolic pressure, CPP — central pulse pressure, CSP — central systolic pressure, DBP — diastolic blood pressure, MAP — mean arterial pressure, MCAP mean central arterial pressure, $\mathrm{PP}$ — pulse pressure, SBP — systolic blood pressure

Table II. Concentration of creatinine and uric acid in serum, fractional uric acid excretion ( $\left.\mathrm{FE}_{\mathrm{UA}}\right)$ and estimated glomerular filtration rate (eGFR) in the studied and the control group

\begin{tabular}{l|c|c|c|c|c}
\hline \multirow{2}{*}{ Parameter } & \multicolumn{2}{c}{$\begin{array}{c}\text { Studied group } \\
\mathrm{n}=\mathbf{2 5}\end{array}$} & \multicolumn{2}{c}{$\begin{array}{c}\text { Control group } \\
\mathrm{n}=15\end{array}$} & SD \\
\cline { 2 - 6 } & \multicolumn{2}{c}{ Mean } & \multicolumn{2}{c}{ SD } & \multicolumn{2}{c}{ Mean } & 0.17 & 0.5889 \\
\hline Creatinine $[\mathrm{mg} \%]$ & 0.87 & 0.14 & 0.90 & 12.37 & 0.5579 \\
\hline eGFR $\left[\mathrm{ml} / \mathrm{min} / 1.73 \mathrm{~m}^{2}\right]$ & 94.42 & 14.56 & 91.76 & 1.12 & 0.3339 \\
\hline Uric acid $[\mathrm{mg} \%]$ & 4.64 & 1.56 & 4.19 & 2.77 & 0.5603 \\
\hline $\mathrm{FE}_{\mathrm{UA}}(\%)$ & 5.00 & 4.12 & 5.71 & & \\
\hline
\end{tabular}

Table III. 24-hour NAG excretion in urine, concentration of erythropoietin, vitamin $25(\mathrm{OH}) \mathrm{D}_{3}$ and $1,25(\mathrm{OH})_{2} \mathrm{D}_{3}$ in serum in the studied and the control group

\begin{tabular}{l|c|c|c|c|c}
\hline \multirow{2}{*}{ Parameter } & \multicolumn{2}{c}{$\begin{array}{c}\text { Studied group } \\
\mathbf{n}=25\end{array}$} & \multicolumn{2}{c}{$\begin{array}{c}\text { Control group } \\
\mathbf{n}=15\end{array}$} & Redian \\
\cline { 2 - 6 } & \multicolumn{2}{c}{ Median } & \multicolumn{2}{c}{ Range } & \multicolumn{2}{c}{ Range } \\
\hline NAG [IU/g creat.] & 2.24 & $0.12-8.74$ & 1.28 & $0.13-2.41$ & 0.0792 \\
\hline Erythropoietin [ug/ml] & 3.55 & $0.24-47.77$ & 4.03 & $0.24-101.00$ & 0.6957 \\
\hline $25(\mathrm{OH}) \mathrm{D}_{3}[\mathrm{ng} / \mathrm{ml}]$ & 15.10 & $7.16-48.70$ & 16.00 & $9.68-40.50$ & 0.5859 \\
\hline $1,25(\mathrm{OH})_{2} \mathrm{D}_{3}[\mathrm{pg} / \mathrm{ml}]$ & 51.50 & $26.40-88.40$ & 49.80 & $29.50-90.60$ & 0.9889 \\
\hline $1,25(\mathrm{OH})_{2} \mathrm{D}_{3} / 25(\mathrm{OH}) \mathrm{D}_{3}$ & 3.03 & $1.36-8.67$ & 3.26 & $1.58-6.25$ & 0.8779 \\
\hline
\end{tabular}

In the group of hypertensive patients, a statistically significant moderate positive correlation was found between aortic PWV and 24-hour NAG excretion $(\mathrm{R}=0.46, \mathrm{p}=0.019)$. The correlation is presented in Figure 1. No such correlation was found in the control group.
In the group of hypertensive patients, a moderate positive correlation at the borderline of statistical significance was found between IMT and 24-hour NAG excretion $(\mathrm{R}=0.46, \mathrm{p}=0.078)$. The correlation is presented in Figure 2. No such correlation was found in the control group. 
Table IV. Left ventricular ejection fraction (EF), left ventricular mass index (LVMI) and ratio of early (E) to late (A) ventricular filling velocities $(E / A)$ in the studied and the control group

\begin{tabular}{|c|c|c|c|c|c|}
\hline \multirow[t]{2}{*}{ Parameter } & \multicolumn{2}{|c|}{$\begin{array}{l}\text { Studied group } \\
\quad n=25\end{array}$} & \multicolumn{2}{|c|}{$\begin{array}{c}\text { Control group } \\
n=15\end{array}$} & \multirow[t]{2}{*}{$\mathbf{P}$} \\
\hline & Mean & SD & Mean & SD & \\
\hline $\mathrm{EF}(\%)$ & 65.20 & 2.22 & 65.47 & 1.36 & 0.6770 \\
\hline LVMI $\left[\mathrm{g} / \mathrm{m}^{2}\right]$ & 96.77 & 18.59 & 88.81 & 16.67 & 0.1814 \\
\hline$E / A$ & 1.09 & 0.26 & 1.28 & 0.19 & 0.0210 \\
\hline
\end{tabular}

Table V. Parameters of vascular structure and function in the studied and the control group.

\begin{tabular}{|c|c|c|c|c|c|}
\hline \multirow[t]{2}{*}{ Parameter } & \multicolumn{2}{|c|}{$\begin{array}{l}\text { Studied group } \\
n=25\end{array}$} & \multicolumn{2}{|c|}{$\begin{array}{c}\text { Control group } \\
n=15\end{array}$} & \multirow[t]{2}{*}{$\mathbf{P}$} \\
\hline & Mean & SD & Mean & SD & \\
\hline IMT [mm] & 0.73 & 0.19 & 0.53 & 0.11 & 0.0011 \\
\hline $\mathrm{PWV}$ [m/s] & 7.86 & 1.60 & 6.50 & 1.12 & 0.0065 \\
\hline Alx (\%) & 24.60 & 13.19 & 15.73 & 13.46 & 0.0480 \\
\hline AP $[\mathrm{mmHg}]$ & 11.76 & 7.77 & 6.33 & 5.29 & 0.0220 \\
\hline
\end{tabular}

Hypertensive subjects demonstrated statistically significant higher values of IMT, aortic PWV, Alx and AP than the control group.

Abbreviations: Aix — augmentation index, AP — augmentation pressure, IMT — intima-media thickness, PWV — pulse wave velocity

Table VI. Spearman's correlation coefficients between PP and parameters of vascular and left ventricular structure and function in the studied and the control group

\begin{tabular}{l|c|c|c|c}
\hline & \multicolumn{2}{c}{$\begin{array}{c}\text { Studied group } \\
\mathbf{n}=25\end{array}$} & \multicolumn{2}{c}{$\begin{array}{c}\text { Control group } \\
\mathbf{n}=15\end{array}$} \\
\cline { 2 - 6 } & $\mathbf{R}$ & $\mathbf{P}$ & \multicolumn{2}{c}{$\mathbf{P}$} \\
\hline PP vs IMT & 0.04 & 0.833 & -0.09 & 0.752 \\
\hline PP vs PWV & 0.15 & 0.473 & 0.31 & 0.262 \\
\hline PP vs Alx & 0.10 & 0.626 & -0.29 & 0.289 \\
\hline PP vs EF & -0.03 & 0.886 & -0.36 & 0.184 \\
\hline PP vs LVMI & -0.02 & 0.937 & 0.19 & 0.496 \\
\hline PP vs E/A & -0.06 & 0.762 & -0.09 & 0.740 \\
\hline
\end{tabular}

A multiple regression analysis was carried out (Tables VIII-X) in which the relationship was studied of vascular structure and function parameters (PWV, IMT), eGFR and uric acid concentration in serum with the rate of 24-hour NAG excretion.

The multiple regression equation is as follows:

$\mathrm{NAG}=-5.39+5.00 \times \mathrm{IMT}+0.51 \times \mathrm{PWV}$

In the group of hypertensive patients, the statistically significant model $(\mathrm{p}=0.00045)$ considers only two independent variables. The correlation between 24-hour NAG excretion and IMT is statistically significant $(\mathrm{p}=0.0048)$ with a mean increase in NAG by $5 \mathrm{IU} / \mathrm{g}$ creatinine and a concomitant increase in IMT by $1 \mathrm{~mm}$. Also, the correlation between 24-hour NAG excretion and PWV is statistically sig- nificant $(\mathrm{p}=0.0158)$ with a mean increase in NAG by $0.51 \mathrm{IU} / \mathrm{g}$ creatinine and a concomitant increase in PWV by $1 \mathrm{~m} / \mathrm{s}$. Standard error of estimation was 1.60 for IMT and 0.19 for PWV. The $\mathrm{R}^{2}$ value of 0.503 indicates that $50.3 \%$ of the variation of 24-hour NAG excretion is explained by the differences in IMT and PWV values.

The additional incorporation of the value of eGFR or uric acid concentration in serum into the model does not have a statistically significant effect on the dependent variable NAG $(\mathrm{p}=0.9307$ and $\mathrm{p}=0.4938$, respectively) (Tables IX and X).

In the control group, the abovementioned parameters have no statistically significant effect on the value of 24-hour NAG excretion. 
Table VII. Spearman's correlation coefficients between CPP and parameters of vascular and left ventricular structure and function in the studied and the control group

\begin{tabular}{l|c|c|c|c}
\hline & \multicolumn{2}{c}{$\begin{array}{c}\text { Studied group } \\
\mathbf{n}=25\end{array}$} & \multicolumn{2}{c}{$\begin{array}{c}\text { Control group } \\
\mathbf{n}=15\end{array}$} \\
\cline { 2 - 6 } & $\mathbf{R}$ & $\mathbf{P}$ & \multicolumn{2}{c}{$\mathbf{P}$} \\
\hline CPP vs IMT & 0.47 & 0.019 & 0.63 & 0.011 \\
\hline CPP vs PWV & 0.13 & 0.544 & 0.33 & 0.234 \\
\hline CPP vs Alx & 0.63 & 0.001 & 0.60 & 0.005 \\
\hline CPP vs EF & 0.12 & 0.553 & -0.16 & 0.480 \\
\hline CPP vs LVMI & 0.33 & 0.103 & -0.12 & 0.669 \\
\hline CPP vs E/A & -0.47 & 0.019 & -0.00 & 0.985 \\
\hline
\end{tabular}

Table VIII. Multiple regression analysis for the dependent variable NAG in the studied group

\begin{tabular}{l|c|c|c}
\hline \multicolumn{2}{l}{ Dependent variable: NAG $\left[\mathrm{UI} / \mathrm{g}_{\mathrm{cr}}\right]$} & \multicolumn{2}{r}{$\mathbf{R}^{2}=\mathbf{0 . 5 0 3}$} \\
\hline Independent variables & \multicolumn{1}{c}{ BETA } & BETA error & $\mathbf{P}$ \\
\hline IMT [mm] & 0.49 & 0.16 & 0.0048 \\
\hline PWV [m/s] & 0.41 & 0.16 & 0.0158 \\
\hline
\end{tabular}

Table IX. Multiple regression analysis for the dependent variable NAG with regard to eGFR in the studied group

\begin{tabular}{l|c|c|c}
\hline \multicolumn{2}{l}{ Dependent variable: NAG [UI/g cr] } & \multicolumn{2}{c}{$\mathbf{R}^{2}=0.514$} \\
\hline Independent variables & BETA & BETA error & P \\
\hline IMT [mm] & 0.47 & 0.16 & 0.0079 \\
\hline PWV [m/s] & 0.42 & 0.16 & 0.0148 \\
\hline eGFR [ml/min/1.73 m²] & 0.11 & 0.15 & 0.4937 \\
\hline
\end{tabular}

\section{Discussion}

The results of the present study confirm the observations to date whereby the values of SBP and PP are higher in the brachial artery as compared to CSP and CPP in both the group of hypertensive subjects and the control group (Table I).

An increase in SBP and PP values along the course of vessels from the heart to the periphery called the augmentation phenomenon results from:

- the propagation of pulse wave through the vascular bed characterized by vascular diameter reduction and the transition from elastic arteries to muscular arteries, and

- the interference between reflected and incident waves resulting from blood being ejected from the left ventricle and flowing in the direction opposite to the wave reflected from arterial bifurcations and choke vessels.
Table X. Multiple regression analysis for the dependent variable NAG with regard to uric acid concentration in blood serum in the studied group

\begin{tabular}{l|c|c|c}
\hline \multicolumn{2}{l}{ Dependent variable: NAG [UI/g cr] } & \multicolumn{2}{c}{$\mathbf{R}^{2}=\mathbf{0 . 5 0 3}$} \\
\hline Independent variables & \multicolumn{1}{c}{ BETA } & BETA error & P \\
\hline IMT [mm] & 0.48 & 0.16 & 0.0062 \\
\hline PWV [m/s] & 0.41 & 0.16 & 0.0192 \\
\hline Uric acid [mg/dl] & -0.01 & 0.16 & 0.9307 \\
\hline
\end{tabular}

In physiological conditions, provided that arterial wall elasticity is maintained, the velocity of a pulse wave is relatively low. Thus, the reflected wave returns to the ascending aorta in diastole, increasing CDP and the flow of blood through coronary vessels [9]. An increase in arterial wall stiffness, leading to an increase in PWV, results in an earlier return of the reflected wave which reaches the ascending aorta and thus induces an increase in CSP. This in turn results in an increase in the left ventricular afterload and a disturbance in the blood flow in coronary vessels [9]. The described pathophysiological mechanism may be considered an argument supporting the assumption that central pressure has a higher predictive value for the occurrence of cardiovascular events than pressure measured conventionally in the brachial artery.

Central pulse pressure is considered to be one of the major indicators associated with cardiovascular complications [10]. Analysis of results of the present study shows that in both the group of hypertensive patients and the control group statistically significant positive correlations were determined between CPP and the values of IMT and AIx (Table VII). Such correlations were not found with respect to peripheral pulse pressure in the brachial artery (Table VI). An increase in IMT, considered to be an early stage 

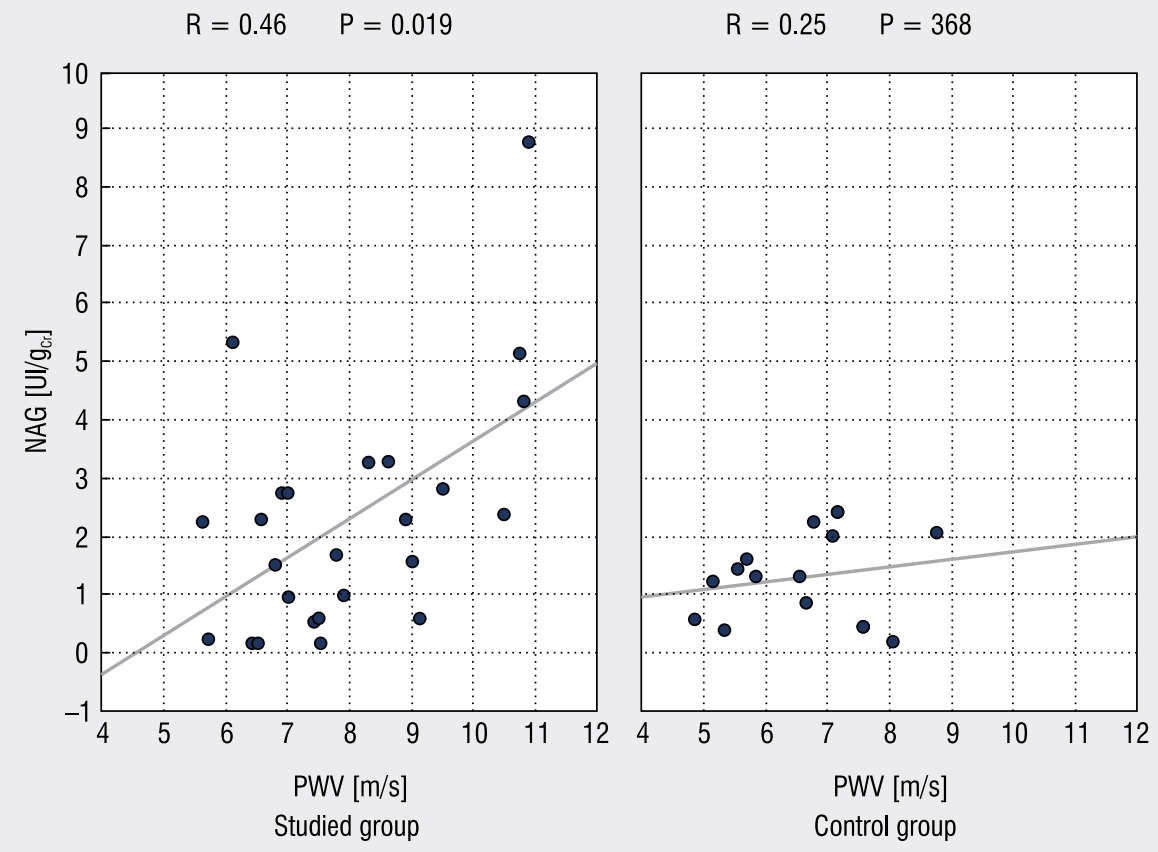

Figure 1. Correlation between 24-hour NAG excretion and PWV in the studied and the control group

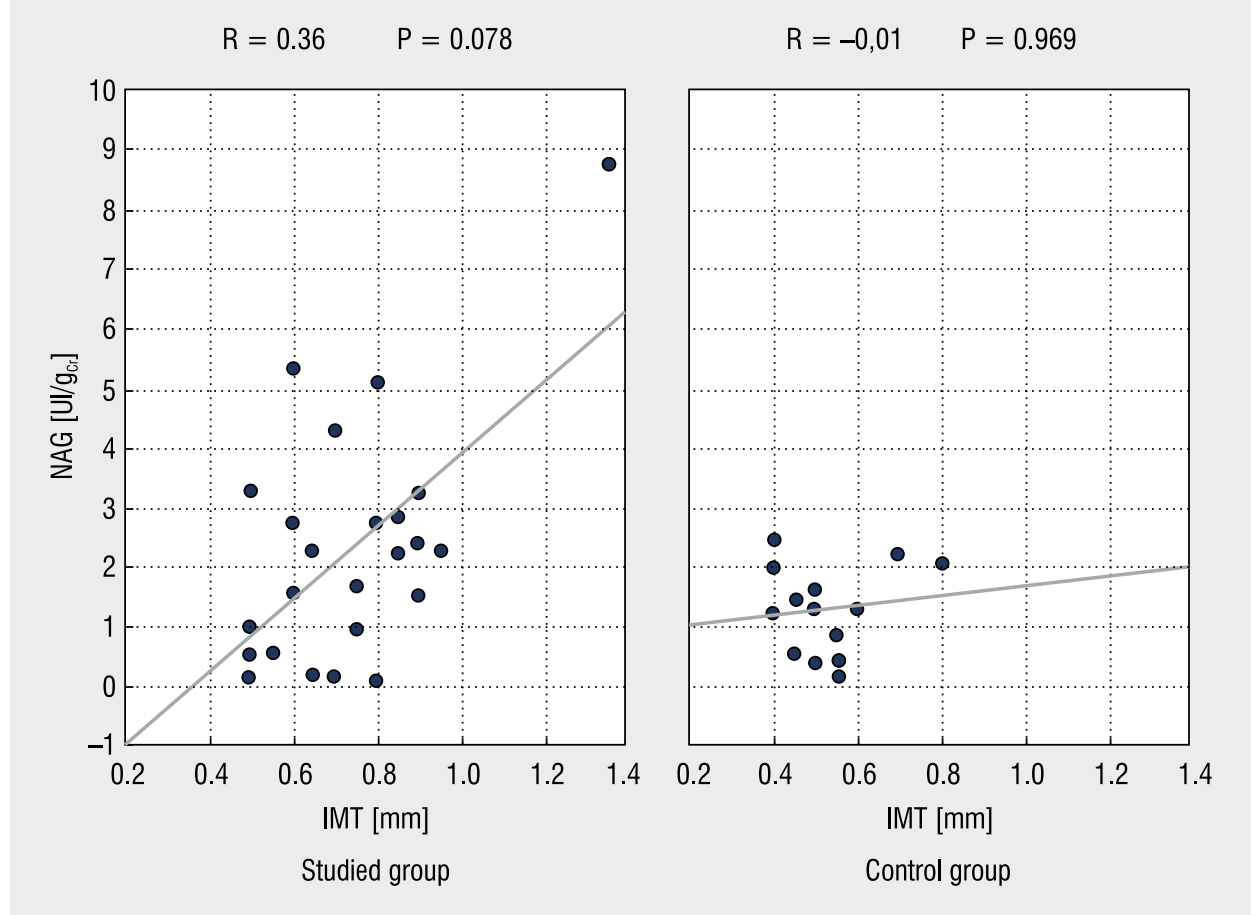

Figure 2. Correlation between 24-hour NAG excretion and IMT in the studied and the control group

of atherosclerosis, was recognized as an indicator of the atherosclerotic process taking place in other arteries [11].
Research study carried out by Boutouyrie et al. [12] on a group of subjects with normal arterial pressure values and patients with previously untreated 
primary arterial hypertension revealed that $\mathrm{CPP}$ in the carotid artery, measured by applanation tonometry, proved to be a reliable indicator of its distensibility and thickness in comparison to PP in the brachial artery and MAP. The determination of a correlation between IMT and PP in an elastic artery, such as the carotid artery, which has not been observed with respect to the radial artery, may indicate the involvement of cyclically changing vascular wall tension in the process of vascular remodelling [12].

A metaanalysis of 11 prospective research studies investigating the correlation between central pressure and patient prognosis showed that an increase in CSP and CPP by $10 \mathrm{mmHg}$ entailed an increase in the risk of the occurrence of a total number of fatal and nonfatal cardiovascular events by $8.8 \%$ for CSP and by $13.7 \%$ for CPP [13]. The additional predictive value of CPP as compared to PP in the brachial artery was only marginal and statistically insignificant $(\mathrm{p}=0.057)[13]$.

Attention should be drawn to the fact that the present study revealed increased, at the borderline of statistical significance, 24-hour excretion of NAG in the group of hypertensive patients as compared to the control group (Table III). NAG is a lysosomal enzyme exhibiting particularly high activity in proximal tubule cells. Due to its high molecular weight - about $140,000 \mathrm{Da}$ - it does not pass through the filter of a normal glomerular basement membrane [14]. NAG activity assessment can be applied as a sensitive and early indicator of proximal tubule damage. Consequently, increased excretion of NAG in hypertensive patients may be indicative of renal tubular defect. The present study failed to determine whether this is a consequence of arterial hypertension or whether its occurrence was preceded by interstitial damage. Arterial hypertension diagnosed in the said group of patients as primary may in fact be a consequence of slight damage to renal tubules whereby glomerular filtration is not impaired and urinalysis results are normal.

Cowley et al. suggest that what underlies arterial hypertension development are hemodynamic disorders leading to microcirculation disorders within the renal medulla [15]. Positive correlations of IMT and PWV with 24-hour NAG excretion discovered in the present study may indicate concomitant damage to renal tubules along with an impairment of vascular morphology and function. It is worth devoting attention to studies which examined the correlation of IMT with the value of the resistive index (RI) in intrarenal vessels [16] or the presence of albuminuria. Bigazzi et al. found a strong positive correlation between IMT and albuminuria [17], which has not, however, been confirmed by other authors [18].

A study by Takiuchi et al. [19] on a group of patients with primary arterial hypertension revealed a statistically significant positive correlation of IMT with albuminuria, the progression of hypertensive retinopathy and LVMI. One of the mechanisms underlying the coexistence of micro- and macroangiopathic changes in those patients might be the involvement of a chronic inflammatory response.

A parameter indicating early changes in the course of arterial hypertension is the RI of intrarenal vessels. An increase in its value reflects an increase in flow resistance of the renal circulation resulting from the stiffening of small arterioles. Therefore, revealing the correlation between IMT and RI in patients with untreated primary arterial hypertension [16] indirectly contributes to explaining the correlation between IMT and 24-hour NAG excretion found in the present study.

The performed multiple regression analysis showed that the parameter which had the strongest effect on the dependent variable NAG in the group of hypertensive patients were the values of PWV and IMT. Uric acid concentration in serum and eGFR showed a marginal, statistically insignificant effect on the dependent variable NAG (Tables VIII-X).

Another parameter determining the functional status of the tubulointerstitial tissue is hormone concentration in serum: vitamin $1,25(\mathrm{OH})_{2} \mathrm{D}_{3}$ and erythropoietin. The kidneys provide the basic source of $1,25(\mathrm{OH})_{2} \mathrm{D}_{3}$ and erythropoietin in the organism. $25(\mathrm{OH}) \mathrm{D}_{3}$ is hydroxylated in position 1 in the proximal tubule mitochondria, whereas erythropoietin is produced mainly by periurethral cells and fibroblasts on the border between the renal cortex and the outer region of the renal medulla. The present study found no statistically significant differences in $1,25(\mathrm{OH})_{2} \mathrm{D}_{3}$ and erythropoietin concentration in serum between the studied groups.

The role of vitamin $\mathrm{D}_{3}$ and its relationship with arterial hypertension are not entirely clear. What testifies to the role of vitamin $\mathrm{D}_{3}$ in arterial pressure regulatory processes is the fact that receptors for vitamin $\mathrm{D}_{3}$ are located in organs participating in arterial pressure regulation, that is in the central nervous system, the kidney, adrenal glands, vascular wall, or the heart [20]. By affecting immune system constituents, vitamin $\mathrm{D}_{3}$ may exert an indirect effect on arterial pressure regulation and the occurrence of cardiovascular diseases. Its influence on the immune system manifests in an inhibitory effect on the maturation of antigen-presenting cells [21] and a modulatory effect 
on the profile of secreted cytokines. It triggers, inter alia, an increase in the production of IL-10 and a decrease in the production of IL-6, IL-12, INF- $\gamma$ and TNF- $\alpha$ [22]. This in turn contributes to a decrease in the production of superoxides and acute-phase proteins, including CRP, and in the proliferation of vascular smooth muscle cells, and has a protective effect on the vascular endothelium.

\section{Conclusions}

1. Damage to the renal tubulointerstitial tissue is concomitant with a decrease in vascular resistance in patients with untreated primary arterial hypertension.

2. An increase in NAG excretion in urine under normoalbuminuria and normal glomerular filtration rates may be indicative of damage to the renal tubulointerstitial tissue preceding damage to glomeruli in those patients.

3. Central pulse pressure may be a useful parameter for assessing the development of atherosclerotic lesions in vessels and the function of the left ventricle of the heart.

\section{Conflict of interest statement}

The authors declare no conflict of interest.

\section{Acknowledgements}

The authors gratefully acknowledge the support of the NERKADAR Foundation.

\section{References}

1. Temmar M., Jankowski P., Peltier M. et al. Intraaortic pulse pressure amplification in subjects at high coronary risk. Hypertension 2010; 55: 327-332.

2. Safar M.E., Blacher J., Protogerou A., Achimastos A. Arterial stiffness and central hemodynamics in treated hypertensive subjects according to brachial blood pressure classification. J. Hypertens. 2008; 26: 130-137.

3. Mancia G., Fagard R., Narkiewicz K. et al. 2013 ESH/ESC Guidelines for the management of arterial hypertension. The Task Force for the Management of Arterial Hypertension of the European Society of Hypertension (ESH) and of the European Society of Cardiology (ESC). Eur. Heart J. 2013; 34: 2159-2219.
4. McEniery C.M., Yasmin, McDonnell B. et al. Central pressure: variability and impact of cardiovascular risk factors: The Anglo-Cardiff Collaborative Trial II. Hypertension 2008; 51: 1476-1482.

5. Czekalski S., Oko A. Rola nerek w patogenezie pierwotnego nadciśnienia tętniczego. Czekalski S. Rutkowski B. (ed.) Nefropatia nadciśnieniowa. Termedia Wydawnictwo Medyczne, Poznań 2007: 40-48.

6. Johnson R.J., Herrera-Acosta J., Schreiner G.F., Rodriguez-Iturbe B. Subtle acquired renal injury as a mechanism of salt-sensitive hypertension. N. Engl. J. Med. 2002; 346: 913-923.

7. Deverux R.B., Koren M.J., De Simone G., Okin P.M., Kligfield P. Methods of detection of left ventricular hypertrophy: Application to hypertensive heart disease. Eur. Heart J. 1993; 14 (suppl. D): 8-15.

8. Levey A.S., Bosch J.P., Lewis J.B., Greene T., Rogers N., Roth D. A more accurate method to estimate glomerular filtration rate form serum creatinine: a new prediction equation. Modification of Diet in Renal Disease Study Group. Ann. Intern. Med. 1999; 130: 461-470.

9. Safar M.E., Jankowski P. Central blood pressure and hypertension: role in cardiovascular risk assessment. Clin. Sci. 2009; 116: 273-282.

10. Pędzich E., Szmigielski C., Gaciong Z. Central blood pressure as a risk marker for cardiovascular complications. Arterial Hypertension 2006; 10: 341-349.

11. Grobbee D.E., Bots M.L. Carotid artery intima-media thickness as an indicator of generalized atherosclerosis. J. Int. Med. 1994; 236: $567-573$

12. Boutouyrie P., Bussy C., Lacolley P., Girere X., Laloux B., Laurent S. Association between local pulse pressure, mean blood pressure, and large-artery remodeling. Circulation 1999; 100: 1387-1393.

13. Vlachopoulos C., Aznaouridis K., O’Rourke M. F., Safar M. E., Baou K., Stefanadis C. Prediction of cardiovascular events and all-cause mortality with central haemodynamics: a systematic review and meta-analysis. Eur. Heart J. 2010; 31: 1865-1871.

14. Szechiński J., Wiland P. N-acetyl- $\beta$-D-glucosaminidase urinary excretion as a parameter of renal proximal dysfunction in patients with renal failure. Pol. Arch. Med. Wewn. 1997, 98: 534-541.

15. Cowley A.W. Jr, Mattson D.L., Lu S., Roman R.J. The renal medulla and hypertension. Hypertension 1995; 25: 663-673.

16. Pontremoli R., Viazzi F., Martinolo C. et al. Increased renal resistive index in patients with essential hypertension: a marker of target organ damage. Nephrol. Dial. Transplant. 1999; 14: 360-365.

17. Bigazzi R., Bianchi S., Nenci R., Baldari D., Baldari G., Compese V.M. Increased thickness of the carotid artery in patients with essential hypertension and microalbuminuria. J. Hum. Hypertens. 1995; 9: 827-833.

18. Pedrinelli R., Dell'Omo G., Penno G. Dissociation between microalbuminuria and common carotid thickness in essential hypertensive men. J. Hum. Hypertens. 2000; 14: 831-835.

19. Takiuchi S., Kamide K., Miwa Y. Diagnostic value of carotid intima-media thickness and plaque score for predicting target organ damage in patients with essential hypertension. J. Hum. Hypertens. 2004; 18: 17-23.

20. Bednarski R., Donderski R., Manitius J. Role of vitamin $D_{3}$ in arterial blood pressure control. Pol. Merk. Lek. 2007; 23: 136, 307-310.

21. Griffin M.D., Lutz W., Phan V.A. et al. Dendritic cell modulation by 1 alpha, 25 dihydroxyvitamin $\mathrm{D}_{3}$ and its analogs: A vitamin D receptor-dependent pathway that promotes a persistent state of immaturity in vitro and in vivo. Proc. Natl. Acad. Sci. USA 2001; 98: 6800-6805.

22. Mathieu C., Adorini L. The coming of age of 1,25-dihydroxyvitamin $\mathrm{D}(3)$ analogs as immunomodulatory agents. Trends. Mol. Med. 2002; 8: 174-179. 